\title{
Microstructure and Mechanical Property Evaluation of Aluminum F357 Powder for Cold Spray Applications
}

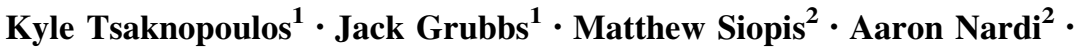 \\ Danielle Cote ${ }^{1}$
}

Submitted: 24 July 2020/in revised form: 11 November 2020/ Accepted: 20 November 2020/Published online: 10 January 2021 (C) The Author(s) 2021

\begin{abstract}
Cold spray (CS) is a solid-state additive manufacturing process that can create high-density, high-performance deposits for many applications. Aluminum alloys have been the target of recent CS research due to their excellent mechanical behavior when cold-sprayed. The introduction of new $\mathrm{Al}$ alloys to $\mathrm{CS}$ is of interest as unique properties may be achieved, especially when powder is heat-treated prior to deposition. In this study, three batches of Al F357 powder-a control as-atomized, heat-treated at $230{ }^{\circ} \mathrm{C}$ for $75 \mathrm{~min}$ and heat-treated at $385{ }^{\circ} \mathrm{C}$ for $6 \mathrm{~h}-$ were studied. Scanning electron microscopy revealed microstructural modifications after heat treatment in the powder and sprayed deposits. X-ray diffraction highlighted the presence of eutectic $\mathrm{Si}, \mathrm{Mg}_{2} \mathrm{Si}$ and $\mathrm{SiO}_{2}$ in all specimens. Energy-dispersive spectroscopy showed the spheroidization of $\mathrm{Si}$ during the $385{ }^{\circ} \mathrm{C}$ heat treatment, with an increase in the fraction of $\mathrm{Mg}_{2} \mathrm{Si}$ during both treatments. Nanohardness and microhardness testing showed a decrease in hardness with thermal processing in both the powder and sprayed deposits. Tensile testing demonstrated ductile behavior from both heat-treated powders, but significantly higher strengths from the $230{ }^{\circ} \mathrm{C}$ treatment. These results suggest Al F357 may be used in CS when appropriate powder heat treatments are applied.
\end{abstract}

Keywords aluminum F357 - cold spray - heat treatment . microstructure $\cdot$ mechanical properties $\cdot$ nanoindentation . powder

Kyle Tsaknopoulos

klfitzpatricksch@wpi.edu; kltsaknopoulos@wpi.edu

Worcester Polytechnic Institute, Worcester, MA, USA

2 US Army Research Laboratory, Aberdeen Proving Grounds, MD, USA

\section{Introduction}

The emergence of additive manufacturing (AM) over the past two decades has led to significant innovation in a number of industries. The layer-by-layer addition of material in AM processes, combined with the rapid nature of part production, provides distinct benefits in certain applications when compared to a traditional subtractive manufacturing approach (Ref 1). From the wide selection of useable materials to the newfound possibilities of creating complex parts, prominent applications of AM have been seen in the aerospace, automotive, biomedical, energy and environmental sectors (Ref 2-4). While techniques have been implemented to utilize polymers and ceramics in these industries, metals are the most commonly used feedstock materials in AM processes (Ref 5-7).

Metal-based AM usually involves the melting of the feedstock material by an electron or laser beam sourceseveral of these processes include selective laser melting (SLM), electron beam melting (EBM), laser engineered net shaping (LENS) and direct energy deposition (DED) (Ref 3, 8, 9). However, certain processes, such as additive friction stir deposition (AFS) and cold spray (CS), take place below the material's melting temperature, allowing for complete material consolidation without a solid-liquid transition (Ref 10, 11). In addition, processes like CS, for example, do not significantly heat the underlying substrate for long time periods, thus minimizing softening from over-aging, annealing or over-tempering (Ref 12). Indicative of their solid-state nature, these non-beam-based AM processes rely on plastic deformation to produce parts containing microstructures similar to that of their feedstock material, with notable artifacts of processing, such as grain refinement (Ref 13, 14). This contrasts the non-equilibrium microstructures that results from the rapid solidification 
seen in other metal-based AM processes where melting is present (Ref 15, 16). While solid-state processes are not as widely adopted as conventional AM processes, they are still capable of producing fully dense, high-performance parts with speed and precision (Ref 17, 18).

A solid-state AM technique that has been adopted in the aerospace, defense, dental, biomedical and automotive industries is CS. Using this technique, metallic, semimetallic or even polymeric feedstock powder is accelerated through a converging-diverging nozzle at supersonic velocities by an inert carrier gas, typically nitrogen or helium. Material buildup is achieved when these particles impact a substrate above the material's critical velocity, leading to adhesion by severe plastic deformation (Ref 19). Depending on the application, feedstock materials can include aluminum, aluminum alloys, copper and steel powders, among many others. This process was initially used as a technique for restoration and repair of parts but is now also being investigated as an additive process to create near net-shape parts and for structural repair coatings (Ref 20, 21). While CS is capable of producing low-oxide deposits using temperature-sensitive materials, the process is inherently limited in its mechanical performance without processing the feedstock powder pre-spray or treating the deposits post-spray (Ref 22). Aluminum alloy powders have been of great interest for solid-state AM processes, particularly $\mathrm{CS}$, due to their strength-to-weight ratio and compatibility with many components in the aerospace and defense industries (Ref 23). Aluminum powder has been used for dimensional restoration and protection of magnesium aircraft components due to its ability to diminish the corrosion effects on the parts while in use (Ref 24). Ogawa et al. proposed the use of low-pressure aluminum CS coatings as a replacement to welding for crack repair in the aerospace industry ( $\operatorname{Ref} 23$ ).

The feedstock used for CS is commonly gas or plasma atomized powder. Since these powders are atomized, they are cooled at a rate of $1000-10,000^{\circ} \mathrm{C} / \mathrm{s}$, which is considered rapidly solidified (Ref 25). Thus, a non-equilibrium microstructure is expected in the as-atomized powder. This can also include segregation within the microstructure, particularly at the grain boundaries (Ref 26-29). As mentioned above, since the microstructure of the powder is retained throughout the CS process and directly influences the final properties of the cold-sprayed deposit, it is necessary to control the microstructure of the powder prior to the CS process in order to obtain consistent and predictable mechanical performance in the final part. This is commonly achieved through the use of heat treatments for microstructural manipulation of the powder. Research has been conducted on how thermal treatment of aluminum powders can differ from typical thermal treatments employed on cast or wrought alloys, as well as on how these thermal treatments prior to CS have improved final part performance and processability (Ref 26-31).

Given the importance of microstructural features to the in-process performance of a material, the use of new $\mathrm{Al}$ alloys in AM, in combination with thermal processing, is being explored (Ref 32). One approach of introducing new Al alloys into the scope of AM is through alloying additions, such as scandium (Ref 33). Another avenue is by using Al alloy compositions traditional to other manufacturing processes, such as casting, forging or extrusion (Ref 34). An alloy of recent interest in AM studies is Al F357, which is traditionally used as a casting material. While Al F357 is not utilized as often as its counterpart Al A357, its thermal properties and relatively high strength make it a viable candidate for AM applications. Due to the relative size of the AM community, several suppliers have scaled production of Al F357 powder, increasing the availability of the alloy in powder form (Ref 35-40). In this study, an Al F357 powder was evaluated for its usefulness in CS applications by analyzing the properties of both the powder and cold-sprayed deposits under varying thermal treatments.

\section{Methods}

\section{Powder Details}

The powder used in this study was an Al F357 powder manufactured by Equispheres (Ottawa, Ontario, Canada), which was produced using a proprietary atomization technique and sieved to a size category 45-63 $\mu \mathrm{m}$. Table 1 displays the chemical composition of the powder as measured by direct plasma emission spectroscopy in accordance with ASTM Standard E1097 (Ref 41). This composition is in compliance with the standard composition for Al F357 tabulated in ASTM Standard B108 (Ref 42).

\section{Thermal Processing of Powder}

Thermal treatment of the Al F357 powder was conducted inside a retort using a depurative degassing arrangement. Dry nitrogen gas was cycled into the container, which was brought to vacuum at $\sim 10^{-2}$ Torr. This process repeated every minute. Two thermal treatments were conducted: $230{ }^{\circ} \mathrm{C}$ for $75 \mathrm{~min}(4500 \mathrm{~s})$ at temperature (regular overaging), and $385{ }^{\circ} \mathrm{C}$ for $6 \mathrm{~h}(21,600 \mathrm{~s})$ at temperature (degassing). 
Table 1 Comparison of chemical composition between the ASTM B108 standard and the A1 F357 powder used in this study

\begin{tabular}{lllllllllll}
\hline & wt.\% Al & wt.\% Si & wt.\% Fe & wt.\% Cu & wt.\% Mn & wt.\% Mg & wt.\% Zn & wt.\% Ti & wt.\% Be & wt.\% Other \\
\hline Standard composition & Balance & $6.5-7.5$ & 0.10 & 0.20 & 0.10 & $0.40-0.70$ & 0.1 & $0.04-0.20$ & 0.002 & 0.15 \\
Aluminum F357 powder & Balance & 7.32 & 0.039 & 0.002 & 0.0036 & 0.58 & 0.0038 & 0.12 & $\ldots$ & 0.007 \\
\hline
\end{tabular}

\section{Modeling}

The computational thermodynamic and kinetic modeling software, Thermo-Calc (Stockholm, Sweden), was used in order to predict the secondary phases present inside these powders, as well as their stability under different thermal treatments. The TCAL6 database was utilized to perform both equilibrium and non-equilibrium calculations for the given alloy composition. These results were then compared to the microstructure of the powder.

\section{Characterization}

The powder's particle size distribution (PSD) and morphology were measured using a Microtrac FlowSync system (Microtrac Retsch $\mathrm{GmbH}$, Haan/Duesseldorf, Germany), which combined dynamic image analysis and laser diffraction to capture PSD and morphology trends.

A Panalytical Empyrean x-ray diffractometer (Malvern Panalytical Ltd., Almelo, Overijssel, Netherlands) was used for x-ray diffraction (XRD) measurements with $\mathrm{Cr} \mathrm{K}_{\alpha}$ radiation and a $\mathrm{V}$ filter. The wavelength of the data was converted to $\mathrm{Cu}$ for analysis purposes using the HighScore Plus software. Analysis of the results was also conducted using HighScore Plus.

Samples were compression mounted using a Buehler Simplimet 4000 (Lake Bluff, IL) in phenolic resin. A Buehler Ecomet 300 Grinder-Polisher was used for standard metallurgical preparation, with a final polishing step of $0.05 \mu \mathrm{m}$ colloidal silica. For improved resolution during microscopy, powder samples were ion-milled using argon gas in a JEOL IB-19530CP Cross Section Polisher (CP) (Tokyo, Japan). For this method, the powder was set inside a cold-mounted epoxy, which was fixed between two silicon wafers. This wafer setup was attached to a specimen mounting block using Crystal Bond, where it was later hand-grinded using 1200-grit $\mathrm{SiC}$ paper and milled in the $\mathrm{CP}$ at $6 \mathrm{kV}$ for $2 \mathrm{~h}(7200 \mathrm{~s})$.

Scanning electron microscope (SEM) imaging was conducted using a Zeiss Evo MA-10 SEM (Carl Zeiss AG, Oberkochen, Germany) equipped with a Bruker X Flash Energy-Dispersive Spectroscopy (EDS) Detector $630 \mathrm{M}$ (Bruker Nano GmbH, Berlin, Germany). The backscatter electron micrographs from SEM imaging were used to conduct secondary phase analysis in the Olympus Stream software, whereby contrast thresholding distinguished the light and dark secondary phases from the neutral $\mathrm{Al}$ matrix. Optical micrographs were obtained using an Olympus GX71 inverted metallurgical microscope (Olympus Corporation, Shinjuku City, Tokyo, Japan). Dendrite size was measured from optical micrographs of ten different powder particles for each sample using the linear intercept method on the Olympus Stream software.

\section{Mechanical Testing}

Hardness testing was conducted on all samples; nanoindentation was used on both powder and consolidated samples, and microhardness only on consolidated samples. Microhardness testing was conducted using a Buehler Wilson VH3300 (Buehler, Lake Bluff, IL) with a Vickers indenter tip. Samples were held for about $10 \mathrm{~s}$ at depth using a $0.1 \mathrm{~kg}$-f applied load. Microhardness values were subsequently converted to units of GPa in order to make comparisons with nanoindentation results. Since the geometries of Vickers and Berkovich tips-used for microhardness and nanoindentation testing, respectivelyhave essentially the same contact area and strain fields during indentation, the following conversion can be applied to compare nanoindentation-derived hardness values with those from microhardness testing:

$H_{N I}=0.010582 * H V$,

where $H_{N I}$ is an equivalent nanohardness value in GPa derived from the Vickers microhardness value, $H V$, in kg-f/ $\mathrm{mm}^{2}$. This is consistent with other derivations, as well as applications of nanoindentation and microhardness testing to compare particle properties with bulk properties (Ref $43,44)$.

Nanoindentation was conducted using an iMicro Pro (Nanomechanics, Inc., Oak Ridge, TN, now KLA Instruments, Milpitas, CA) equipped with an InForce $50 \mathrm{mN}$ electromagnetic actuator and a Berkovich diamond indenter tip. The Oliver-Pharr method of tip contact area function calibration was used in this study. A Poisson's ratio of 0.3 was used for the Al-based specimens, and the material properties were reported at an indentation depth of $250 \mathrm{~nm}$. The maximum applied load was held at depth for about $15 \mathrm{~s}$ to account for creep effects at each indent location. As for the nanomechanical method, the continuous stiffness 
measurement-based "Advanced Dynamic E \& H" protocol was implemented. For all powder samples considered, indentation was completed on particle cross sections of comparable diameter. To account for the higher compliance of the phenolic mounting compound with respect to the particles, a particle-dominated indentation depth limit was employed - originally developed by Yan et al. and refined by Sousa et al.- to ensure the mounting material did not influence the measured particle properties as a function of particle diameter and strength (Ref 45, 46).

Tensile testing was conducted at room temperature on the cold-sprayed specimens using an MTS QTest 25 electromechanical load frame. The specimens were machined to a standard tensile coupon geometry, in accordance with the sub-size flat coupon in ASTM Standard E8/E8M (Ref 47). The machine's crosshead speed was $0.05 \mathrm{in} / \mathrm{min}$ $(0.0212 \mathrm{~mm} / \mathrm{s})$ for all specimens tested. The testing was performed using a calibrated MTS $25 \mathrm{kN}$ load cell and MTS 634.31R-25 clip-on extensometer. Marks were made on the test section using a fine permanent marker at a nominal spacing of 1 in $(25.4 \mathrm{~mm})$ to measure elongation. The actual spacing was measured before and after testing using a microscope with micrometer indexing stage and crosshairs for improved accuracy over traditional caliper measurements. After testing, the fracture surface was reassembled to make elongation measurements.

\section{Cold Spray Deposition}

Cold-sprayed deposits were produced using a VRC Gen III system (VRC Metal Systems, Box Elder, SD) equipped with Nozzle \#0071. This nozzle has a throat diameter of $1.75 \mathrm{~mm}$, an exit diameter of $5 \mathrm{~mm}$ and an overall length of $170 \mathrm{~mm}$, with a diverging length of approximately $152 \mathrm{~mm}$. Helium was used as the carrier gas, with a pressure of 50 bar $(5 \mathrm{MPa})$ and temperature of $500{ }^{\circ} \mathrm{C}$ measured at the applicator. Deposition was performed on an $\mathrm{Al} 6061$ substrate at a 1.125 in $(28.575 \mathrm{~mm})$ standoff distance, $200 \mathrm{~mm} / \mathrm{s}$ gun speed and $1 \mathrm{~mm}$ step size, yielding a deposit with a thickness of 0.19 in $(4.826 \mathrm{~mm})$. After deposition, the cold-sprayed Al F357 material was removed from the $\mathrm{Al} 6061$ substrate by machining the $\mathrm{Al}$ 6061 away using a conventional milling process. The Al F357 material was then machined to produce the tensile samples used in this study.

\section{Results and Discussion}

\section{Powder Size and Shape}

The size and morphology of the Al F357 powder used in this study were measured using SEM and a particle size- shape analyzer. The powder was not expected to see any size or shape changes during thermal exposure; thus, only the as-atomized powder was analyzed for size and shape using the SEM and particle size-shape analyzer. Figure 1(a) shows the external surface of the powder particles as seen through SEM. These powder particles are nearly spherical in shape with a consistent diameter, likely a product of their production process, which is proprietary to Equispheres. Also, there are very few satellite particles seen. Figure 1(b) demonstrates the size distribution of the powders with a $D_{10}, D_{50}$ and $D_{90}$ of $47.6 \mu \mathrm{m}, 56.7 \mu \mathrm{m}$ and $73.01 \mu \mathrm{m}$, respectively, which is fairly consistent with the $45-63 \mu \mathrm{m}$ size band given by the manufacturer.

\section{Microstructural Evaluation}

In order to understand the internal microstructure of the powder particles, thermodynamic modeling was used as a guide to show potential phases present at different stages of thermal treatment of the powder. Figure 2(a) shows the non-equilibrium Scheil solidification diagram, which depicts the expected phases present in the as-atomized powder. Scheil solidification models are good predictors for atomized powders since they solidify rapidly, which is where Scheil solidification is most valid (Ref 26-29). The potential phases for the as-atomized powder include Diamond_A4 (a pure eutectic $\mathrm{Si}$ phase), $\mathrm{Mg}_{2} \mathrm{Si}, \mathrm{Al}_{3} \mathrm{Ti}$ and $\mathrm{Al}_{18} \mathrm{Fe}_{2} \mathrm{Mg}_{7} \mathrm{Si}_{10}$. The equilibrium diagram in Fig. 2(b) can be used to aid in identification of potential phases found in the powders as a function of thermal treatment, as well as the stability of those phases at different temperatures. The predicted stable phases at $230{ }^{\circ} \mathrm{C}$ include Diamond_A4, $\mathrm{Mg}_{2} \mathrm{Si}, \mathrm{Al}_{3} \mathrm{Ti}, \mathrm{Al}_{9} \mathrm{Fe}_{2} \mathrm{Si}_{2}$ and $\mathrm{Al}_{15} \mathrm{Si}_{2} \mathrm{Mn}_{4}$, whereas those stable at $385{ }^{\circ} \mathrm{C}$ include Diamond_A4, $\mathrm{Mg}_{2} \mathrm{Si}, \mathrm{Al}_{9} \mathrm{Fe}_{2} \mathrm{Si}_{2}$ and $\mathrm{AlSi}_{2} \mathrm{Ti}_{2}$. The major phases predicted in all thermal treatment conditions are the eutectic Si phase and $\mathrm{Mg}_{2} \mathrm{Si}$. Figure 3 depicts the volume percentage of the major phases present in this powder at the different thermal conditions as predicted by Thermo-Calc. In the as-atomized condition, the powder is about 6.5 vol.\% $\mathrm{Si}$ phase and 0.5 vol.\% $\mathrm{Mg}_{2} \mathrm{Si}$. The predicted volume fraction of both phases increases for both thermal treatments compared with the as-atomized condition. The equilibrium diagram shows that the equilibrium amount of both phases at $230{ }^{\circ} \mathrm{C}$ is slightly higher than the amount at the elevated $385{ }^{\circ} \mathrm{C}$ treatment temperature.

Figure 4(a) demonstrates the internal microstructure of the as-atomized power particles. The secondary SEM micrograph shows the presence of a partially equiaxed dendritic microstructure, with regions of dark script-like phases at the dendrite boundaries and an additional phase shown as small bright white areas. Figure 4(b) depicts the internal microstructure of the powder after a thermal 
Fig. 1 (a) A secondary electron SEM micrograph of external surface of Al F357 powder particles, which are a physical representation of the PSD shown in the (b) histogram
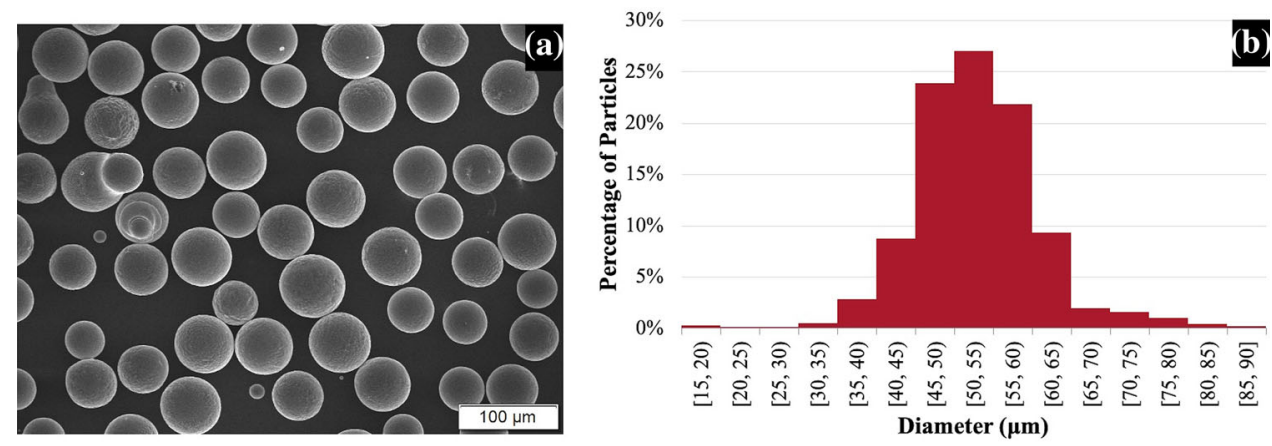
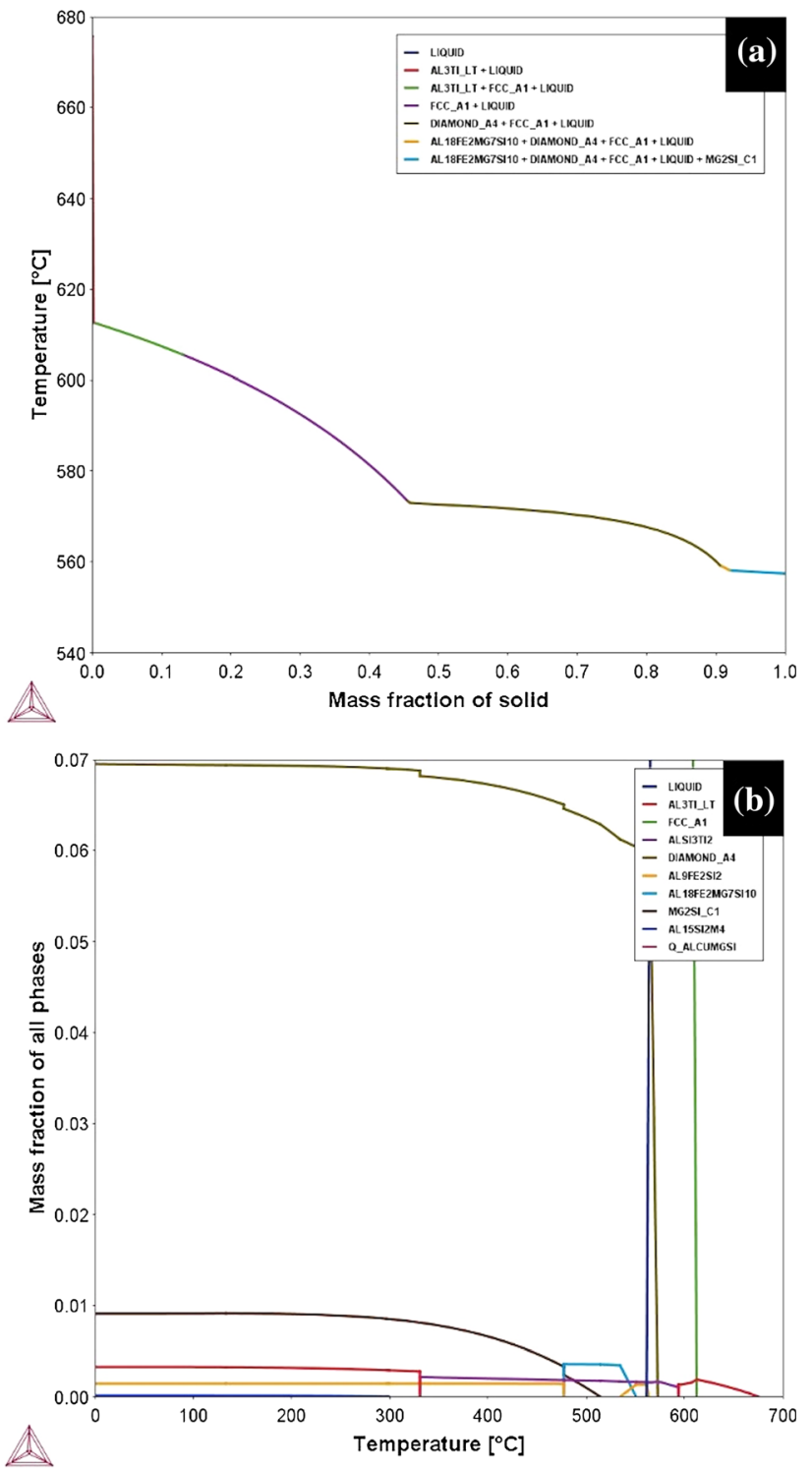

Fig. 2 The (a) Scheil non-equilibrium diagram and (b) Equilibrium diagram calculated from Thermo-Calc

treatment of $230{ }^{\circ} \mathrm{C}$ for $75 \mathrm{~min}$. These micrographs appear to show very little change from the as-atomized microstructure at this temperature and time.
Figure 4(c) shows the internal microstructure of the powder after heat treatment at $385{ }^{\circ} \mathrm{C}$ for $6 \mathrm{~h}$. These micrographs reveal coarsening of both the dark and light contrasting phases at the dendrite boundaries, accompanied with a transition from the networked, script-like phase structure to a more spheroidized structure. Similar trends in microstructural evolution with heat treatment have been seen in other Al-Si-Mg alloys (Ref 48-51). Dendrite size measurements from optical micrographs suggest a trend of growth through prolonged thermal treatments. Compared to the as-atomized powder $(2.75 \pm 0.95 \mu \mathrm{m})$, there was a $4.4 \%$ (to $2.85 \pm 1.06 \mu \mathrm{m}$ ) and a $49.1 \%$ (to $4.07 \pm 1.47 \mu \mathrm{m})$ increase in dendrite size in the $230{ }^{\circ} \mathrm{C}$ and $385{ }^{\circ} \mathrm{C}$ heat-treated powders, respectively. This jump in size is an anticipated occurrence, as seen with other $\mathrm{Al}$ alloys, given boundary motion increases with prolonged times at elevated temperatures toward a trend of dendrite growth (Ref 52). Future studies will be conducted to evaluate how this increase in dendrite size affects the properties of cold-sprayed deposits.

Further assessment of the powder's microstructural changes with heat treatment can be seen using SEM EDS maps, depicted in Fig. 5. The SEM EDS maps of the internal microstructure of the as-atomized powder in Fig. 5(a) show the segregation of $\mathrm{Si}$ and $\mathrm{Mg}$ solute to the dendrite boundaries. This map suggests the presence of two different phases: a Si-rich phase and a $\mathrm{MgSi}$-rich phase. When comparing with the thermodynamic calculations in Fig. 2(a), these phases are likely the diamond Si phase and the $\mathrm{Mg}_{2} \mathrm{Si}$ phase. Figure 5(b) shows the SEM EDS maps for the $230{ }^{\circ} \mathrm{C}$ condition, exhibiting a similar microstructure of the two phases. However, with the $385{ }^{\circ} \mathrm{C}$ heattreated powder, the SEM EDS maps in Fig. 5(c) show the coarsened Si-rich phase at the dendrite boundaries, which is more discrete when compared to the network-like structure in the as-atomized and $230{ }^{\circ} \mathrm{C}$ conditions. This spheroidization of the Si network with thermal processing is an anticipated phenomenon in Al-Si alloys (Ref 53).

In order to confirm the identity of the phases present in the powder, XRD analysis was conducted. The XRD spectra in Fig. 6 confirm the existence of both the eutectic 
Fig. 3 Volume percentage of secondary phases present in each powder microstructure for each thermal treatment condition (as-atomized, $230{ }^{\circ} \mathrm{C}$ and $385^{\circ} \mathrm{C}$ ), as calculated by Thermo-Calc and image analysis of SEM micrographs

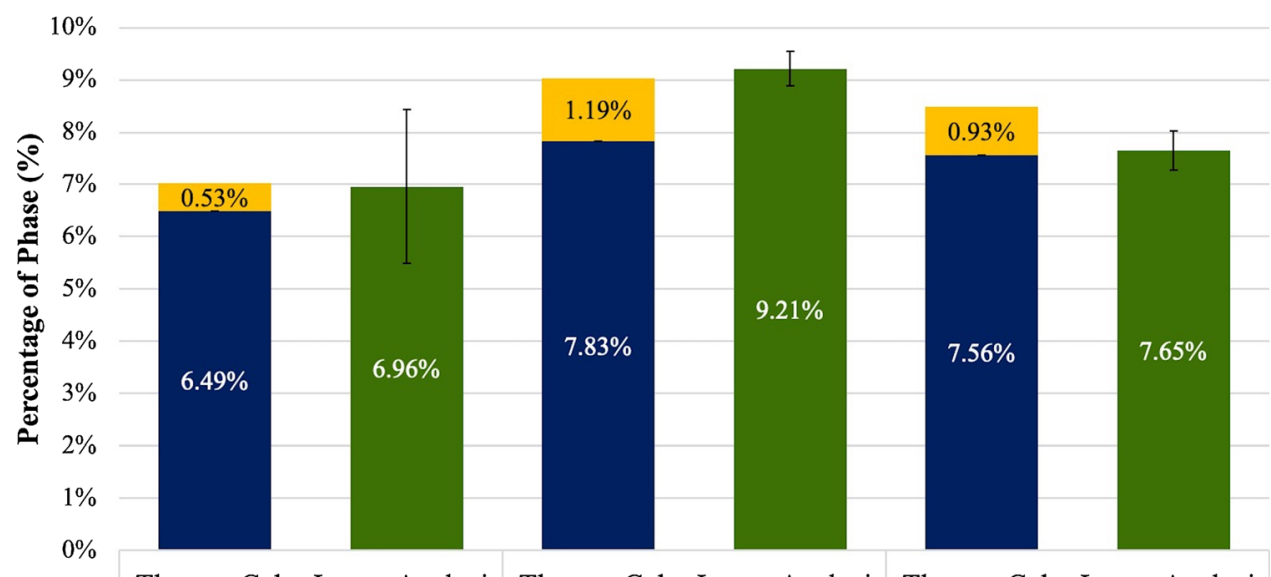

Thermo-Calc Image Analysis Thermo-Calc Image Analysis Thermo-Calc Image Analysis As-Atomized $230^{\circ} \mathrm{C}$ $385^{\circ} \mathrm{C}$

— Si $\square \mathrm{Mg}_{2} \mathrm{Si} \square$ Total Phases
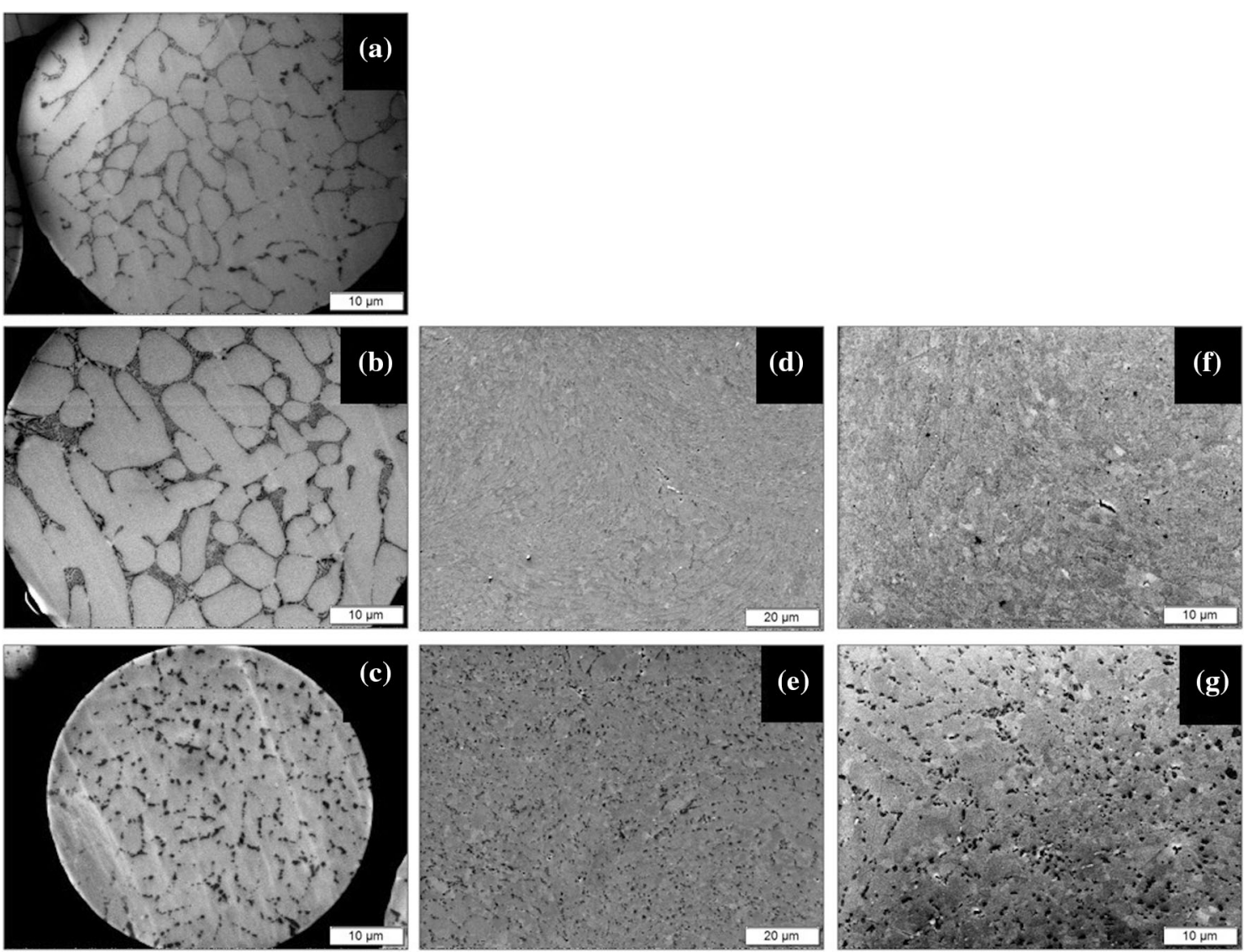

Fig. 4 Secondary electron SEM micrographs of cross sections of (a) As-atomized powder at $2000 \times$ magnification, (b) $230{ }^{\circ} \mathrm{C}$ heattreated powder at $2000 \times$ magnification, (c) $385{ }^{\circ} \mathrm{C}$ heat-treated powder at $2000 \times$ magnification, Cold-sprayed $230{ }^{\circ} \mathrm{C}$ heat-treated

Si phase and the $\mathrm{Mg}_{2} \mathrm{Si}$ phase in all three powders, as was predicted by Thermo-Calc and seen in the SEM EDS maps. The presence of an oxide in the powder was also confirmed with the presence of spectra peaks corresponding to $\mathrm{SiO}_{2}$ powder specimen at (d) $1000 \times$ magnification and (f) $2000 \times$ magnification, and Cold-sprayed $385^{\circ} \mathrm{C}$ heat-treated powder specimen at (e) 1000x magnification and (g) $2000 \times$ magnification

for all powder samples; further investigation in necessary to determine whether this is an outer oxide layer on the particles or an oxide within the powder microstructure. In order to understand how the phases are changing as a 

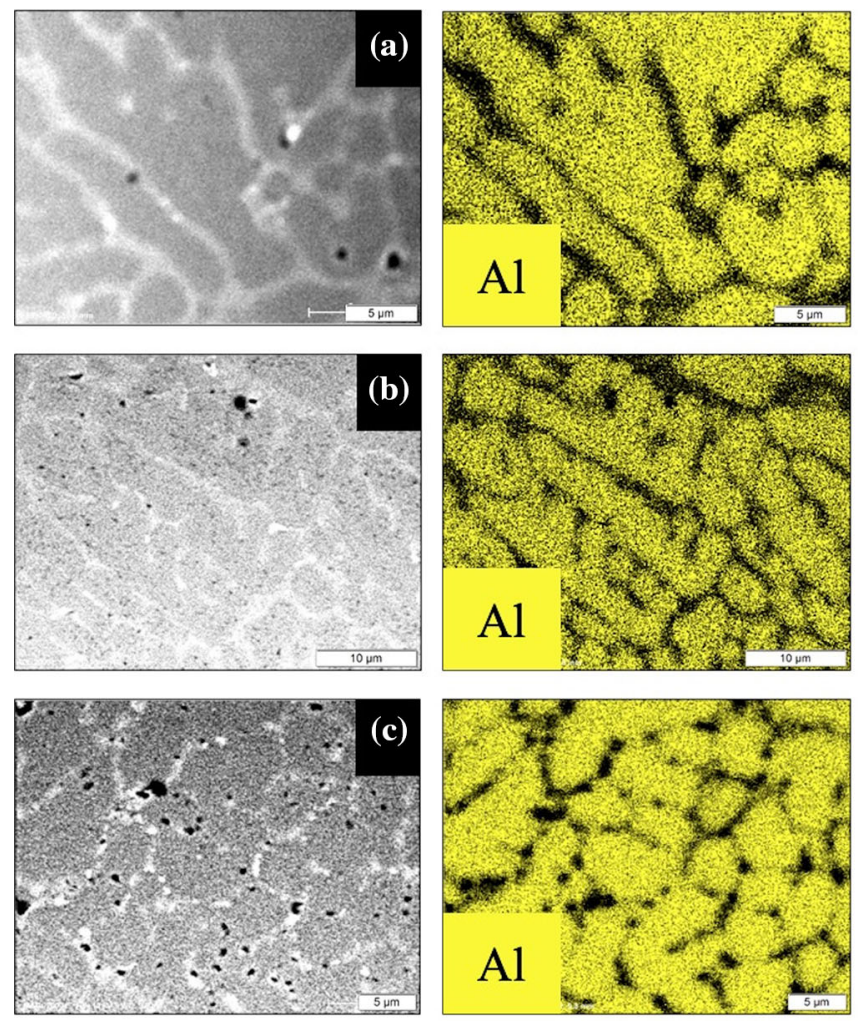
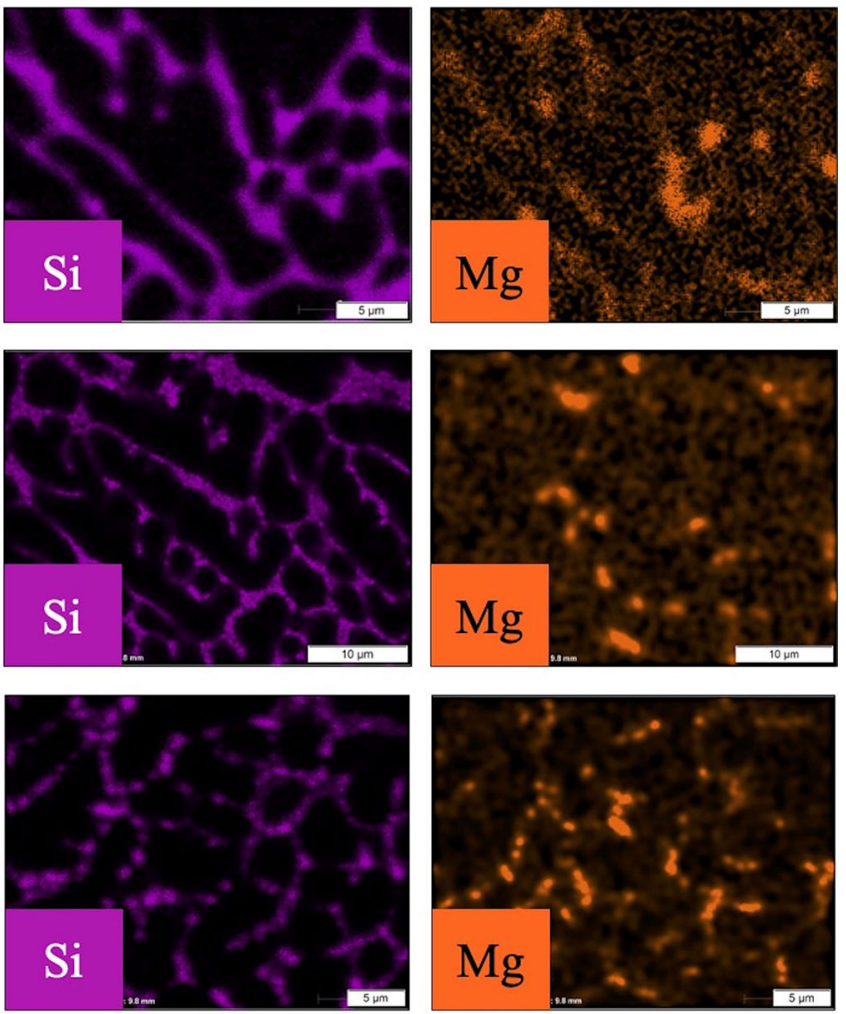

Fig. 5 SEM EDS maps of the (a) As-atomized powder microstructure, (b) $230{ }^{\circ} \mathrm{C}$ heat-treated powder microstructure and (c) $385{ }^{\circ} \mathrm{C}$ heattreated powder microstructure

Fig. 6 XRD spectra for the powder at three heat treatment conditions (as-atomized, $230{ }^{\circ} \mathrm{C}$ and $385^{\circ} \mathrm{C}$ ) and for the coldsprayed specimens with powder at two heat treatment conditions $\left(230{ }^{\circ} \mathrm{C}\right.$ and $\left.385^{\circ} \mathrm{C}\right)$

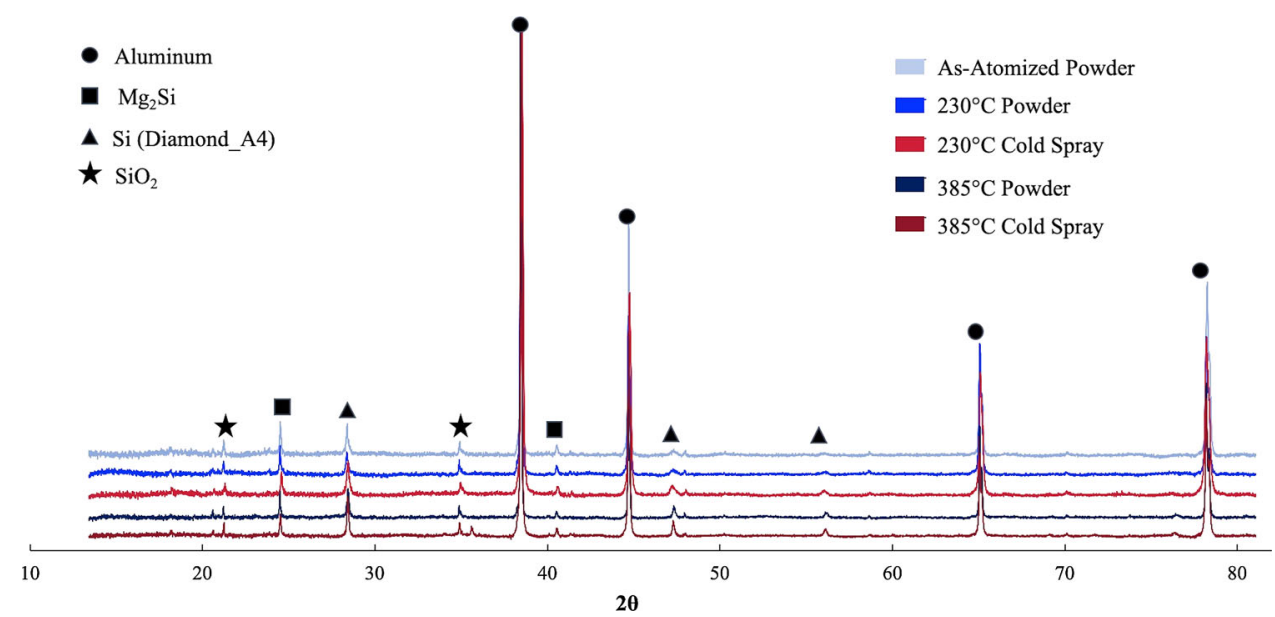

function of the thermal treatment, image analysis was used to quantify the change in the percentage of the secondary phases. The green bars in Fig. 3 show the results of the quantitative secondary phase analysis, as calculated through image analysis of SEM micrographs and compared to the previously discussed results predicted by ThermoCalc. Phase fractions were determined by applying contrast thresholding algorithms to the backscatter SEM micrographs, which leveraged the varied contrast of secondary phases with respect to the grayscale Al matrix. The phase fraction calculated through image analysis is for the total amount of secondary phases, instead of for the two individual phases, since the software was unable to discern the differences between the two in the SEM micrographs. Overall, the trend in the total amount of phases for each powder treatment condition closely matches that predicted by Thermo-Calc. The as-atomized powder contained about 7 vol.\% secondary phases. The amount of phases increased in the powder treated at $230{ }^{\circ} \mathrm{C}$ to about 9 vol.\%, while the powder treated at $385{ }^{\circ} \mathrm{C}$ increased to about 8 vol.\%. This 
trend is expected with the increase in thermal treatment temperature.

The microstructure of the cold-sprayed deposits for the $230{ }^{\circ} \mathrm{C}$ heat-treated powder and the $385{ }^{\circ} \mathrm{C}$ heat-treated powder can also be seen in Fig. 4. A lower magnification is used in Fig. 4(d) and (e) to highlight the nature of particleparticle bonding in the consolidated specimens, whereas a higher magnification is used in Fig. 4(f) and (g) to demonstrate intricacies of the deposit microstructure. In all the SEM micrographs, it can be seen that the initial microstructure of the thermally treated powder has been retained after CS. The same dark and light contrasting phases can be seen in these micrographs. Additionally, both specimens show the severe plastic deformation of the feedstock powder upon deposition, which is a direct result of the high-velocity particle impacts associated with CS processing. The XRD analysis in Fig. 6 for the coldsprayed deposits verifies the presence of the same two phases as the initial powder, $\mathrm{Si}$ and $\mathrm{Mg}_{2} \mathrm{Si}$, confirming that the deposits retain the same microstructure. The presence of the spectra peaks for $\mathrm{SiO}_{2}$ also confirms that at least some of the original oxide associated with the powder is retained within the cold-sprayed deposit's microstructure. Figure 6 also demonstrates some broadening of the spectra peaks for the cold-sprayed deposits, which is likely due to the increased strain in the samples from the CS process. Mechanical property analysis will give insight into how the thermal treatments affect the powder's performance via microstructural changes, which then influence the properties of the cold-sprayed deposits.

\section{Mechanical Property Evaluation}

With the aim of correlating microstructural features to the resulting mechanical properties as a function of heat treatment, hardness testing was employed. Using both conventional microhardness and dynamic nanoindentation techniques, the hardness was evaluated on the powder and cold-sprayed specimens under the varying heat treatment conditions, as seen in Fig. 7. Here, microhardness was used to measure the alloys' bulk properties, while nanoindentation was used to evaluate the presence of microstructural features with higher precision, given the size scale of the phases present. Comparing the powder nanohardness measurements, both heat-treated conditions decreased in hardness when compared to the as-atomized powder, from $1.798 \pm 0.106 \mathrm{GPa}$ to $1.533 \pm 0.186 \mathrm{GPa}$ in the $230{ }^{\circ} \mathrm{C}$ powder and to $1.095 \pm 0.138 \mathrm{GPa}$ in the $385{ }^{\circ} \mathrm{C}$ powder. These results agree with the phase fractions predicted through Thermo-Calc and image analysis, as well as the microstructures seen through SEM micrographs and EDS mapping. As the powders were heat-treated, the $\mathrm{Si}$ and $\mathrm{Mg}_{2} \mathrm{Si}$ phases coarsened, particularly with the $385^{\circ} \mathrm{C}$ heat treatment. These coarsened, spheroidized phases are often incoherent with the matrix, which do not serve as effective impediments to dislocation motion. Therefore, a decrease in hardness is expected. Here, the fraction of these coarsened phases increased with thermal treatment; thus, the decrease in hardness compared to the as-atomized powder is justified. Additionally, calculations of dendrite size showed an increase in size with prolonged thermal treatments; based on the well-known Hall-Petch relationship, the strength (and thus hardness) is expected to decrease with this increase in dendrite size (Ref 54, 55).

The cold-sprayed samples follow a similar trend, with the lowest nanohardness and microhardness for the $385{ }^{\circ} \mathrm{C}$ powder spray $(1.183 \pm 0.127 \mathrm{GPa}$ and $0.654 \pm 0.030$ $\mathrm{GPa}$, respectively) when compared to the $230{ }^{\circ} \mathrm{C}$ powder spray $(1.617 \pm 0.216 \mathrm{GPa}$ and $1.014 \pm 0.034 \mathrm{GPa}$, respectively). An important note is that the microhardness of the cold-sprayed specimens is nearly half that of the nanohardness, on an equivalent scale. This is expected due to the indentation size effect seen in hardness testing, where there is an increase in hardness with decreasing indentation size, particularly at sub-micron scales (Ref 56). Additionally, it is relevant to highlight that the coldsprayed nanohardness is higher than the powder nanohardness in both heat-treated conditions. Due to the
Fig. 7 Powder nanohardness (red) at three heat treatment conditions (as-atomized, $230{ }^{\circ} \mathrm{C}$ and $385^{\circ} \mathrm{C}$ ), and cold-sprayed specimen nanohardness (blue) and microhardness (gray) with powder at two heat treatment conditions $\left(230{ }^{\circ} \mathrm{C}\right.$ and $\left.385{ }^{\circ} \mathrm{C}\right)$

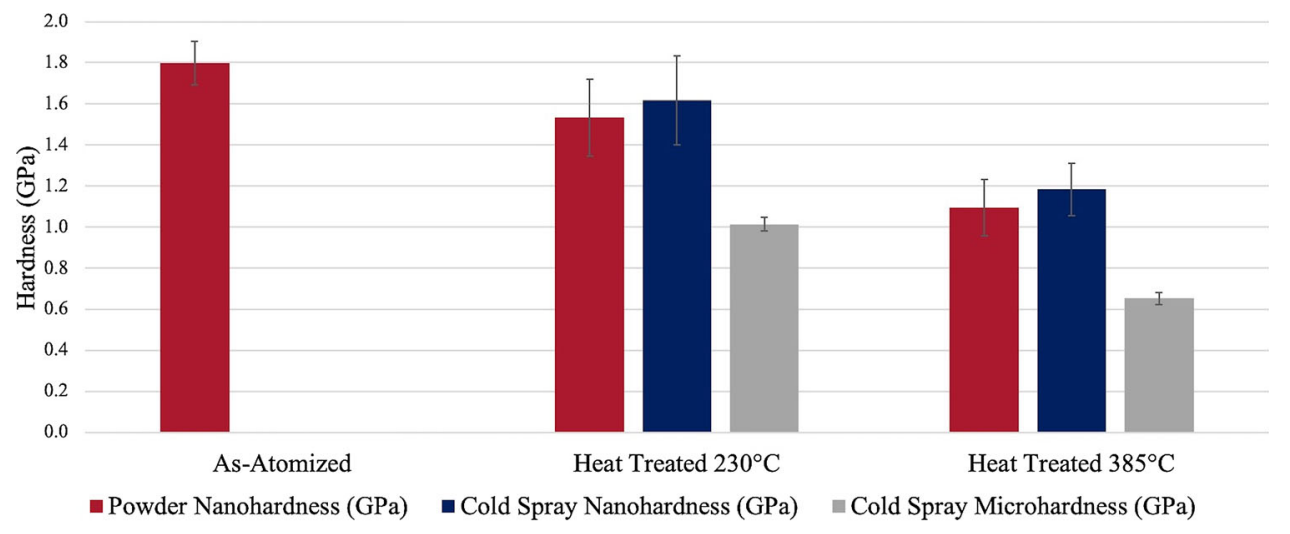


high levels of plastic deformation involved with CS, higher dislocation densities are often observed in the cold-sprayed specimens when compared to the original feedstock powder. Thus, strain hardening of the powder during deposition will result in an increased nanohardness of the coldsprayed deposit (Ref 57-60).

Another form of mechanical testing used to evaluate the cold-sprayed specimens was uniaxial tensile testing. The results of these tests are presented in Fig. 8. The 0.2\% offset yield strength (YS), ultimate tensile strength (UTS) and elongation $(\% \mathrm{El})$ values for the $230{ }^{\circ} \mathrm{C}$ specimen are $262.28 \pm 8.25 \mathrm{MPa}, \quad 293.97 \pm 3.44 \mathrm{MPa} \quad$ and $8.91 \pm 1.50 \%$, respectively, and for the $385^{\circ} \mathrm{C}$ specimen are $\quad 185.98 \pm 5.27 \mathrm{MPa}, \quad 186.58 \pm 5.55 \quad$ and $10.47 \pm 1.40 \%$, respectively. Compared to the tensile properties of traditional Al 357 castings, the cold-sprayed samples exhibited promising results, even when compared to the casting's peak-hardened T6-tempered condition. For example, typical YS, UTS and \%El values for permanent mold cast $\mathrm{Al} 357$ in the as-cast condition are $105 \mathrm{MPa}$, $190 \mathrm{MPa}$ and 6\%, respectively, and in the T6-tempered condition are $295 \mathrm{MPa}, 360 \mathrm{MPa}$ and 5\%, respectively (Ref 61). Here, the mechanical properties of the coldsprayed specimens of both heat-treated powders are comparable to the as-cast condition, with notable improvements in ductility. The $230^{\circ} \mathrm{C}$ specimen approached the YS and UTS of the peak-hardened T6-tempered casting, while still demonstrating increased \%El. These results suggest that CS can produce deposits at least as good as castings, even without heat treatment optimization.

In this study, the stress-strain behavior was quite different for the two different heat treatment conditions, with a $41.03 \%$ increase in YS, $57.56 \%$ increase in UTS and $14.90 \%$ decrease in $\% \mathrm{El}$ from the $385{ }^{\circ} \mathrm{C}$ specimen to the $230{ }^{\circ} \mathrm{C}$ specimen. Given the spray parameters were consistent between the two heat treatment conditions, the difference in cold-sprayed specimens' mechanical properties is likely attributable to the microstructural differences between the two samples. Further work is necessary to see if optimized heat treatments can result in superior mechanical behavior. Although the current heat treatments were not optimized for peak mechanical performance, these results highlight the importance of selecting the appropriate powder thermal treatments for the desired properties of cold-sprayed parts, as changes in heat treatment times and temperatures will dramatically impact part performance.

The fracture surfaces of both cold-sprayed specimens are seen in Fig. 9. Each spray resulted in near complete consolidation, given the highly deformed nature of most particles in the specimens. However, there is evidence in Fig. 9(a) and (c) of undeformed, whole particles remaining after the sprays, which has previously been correlated with unstable fracture conditions (Ref 23). Fractographic analysis shows characteristics of ductile fracture in the consolidated specimens of both heat-treated powders, indicated by the dimpled surfaces, which are likely a product of micro-void coalescence. There are larger and morepronounced dimples in the $385{ }^{\circ} \mathrm{C}$ specimen in Fig. 9(d), compared to the $230^{\circ} \mathrm{C}$ specimen in Fig. 9(b), which correspond well to the lower strengths and higher elongations observed in the tensile tests (Ref 62, 63).

\section{Conclusions}

The present study aimed to evaluate the microstructure and mechanical properties of an Al F357 alloy powder subjected to heat treatments and CS processing. The main conclusions of this work are as follows:

- The presence of $\mathrm{Si}, \mathrm{Mg}_{2} \mathrm{Si}$ and $\mathrm{SiO}_{2}$ phases was confirmed in the Al F357 powders for all thermal conditions using SEM, EDS and XRD. Thermal treatments resulted in the coarsening and
Fig. 8 Measurements of $0.2 \%$ offset yield strength, ultimate tensile strength and elongation from the tensile tests of the cold-sprayed specimens of the $230{ }^{\circ} \mathrm{C}$ heat-treated powder (red) and $385{ }^{\circ} \mathrm{C}$ heat-treated powder (blue)

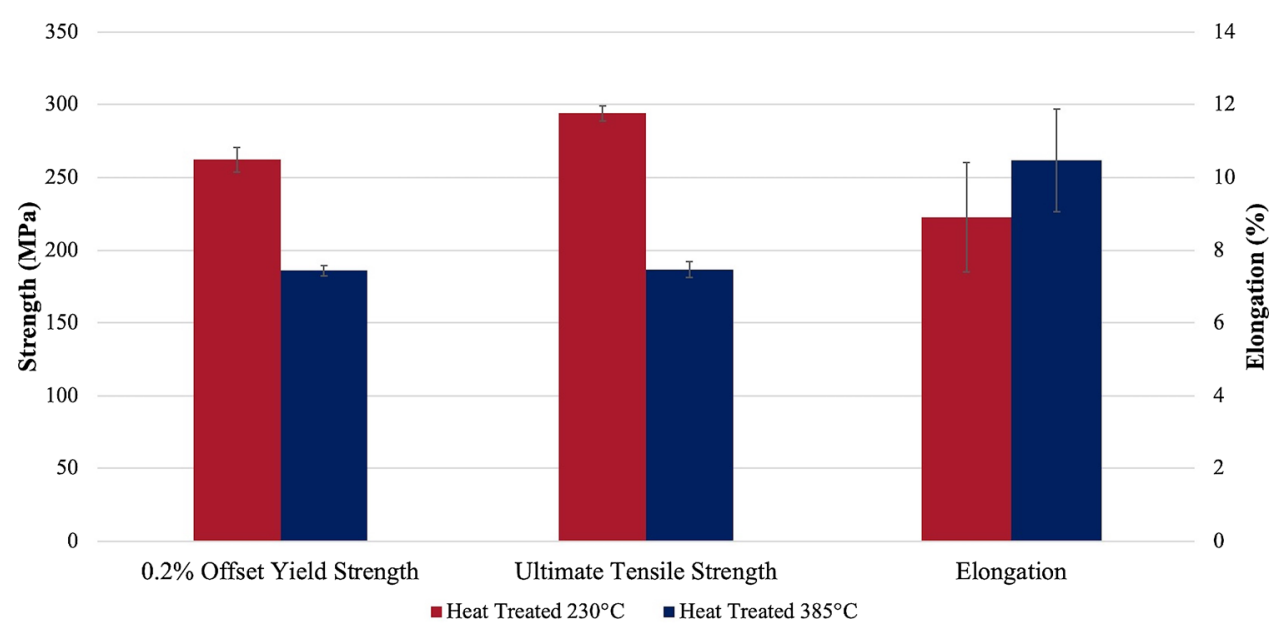


Fig. 9 SEM fractographs of the cold-sprayed tensile specimens of the $230{ }^{\circ} \mathrm{C}$ heat-treated powder at (a) $250 \times$ magnification and (b) $1000 \times$ magnification, and the $385{ }^{\circ} \mathrm{C}$ heat-treated powder at

(c) $250 \times$ magnification and

(d) $1000 \times$ magnification
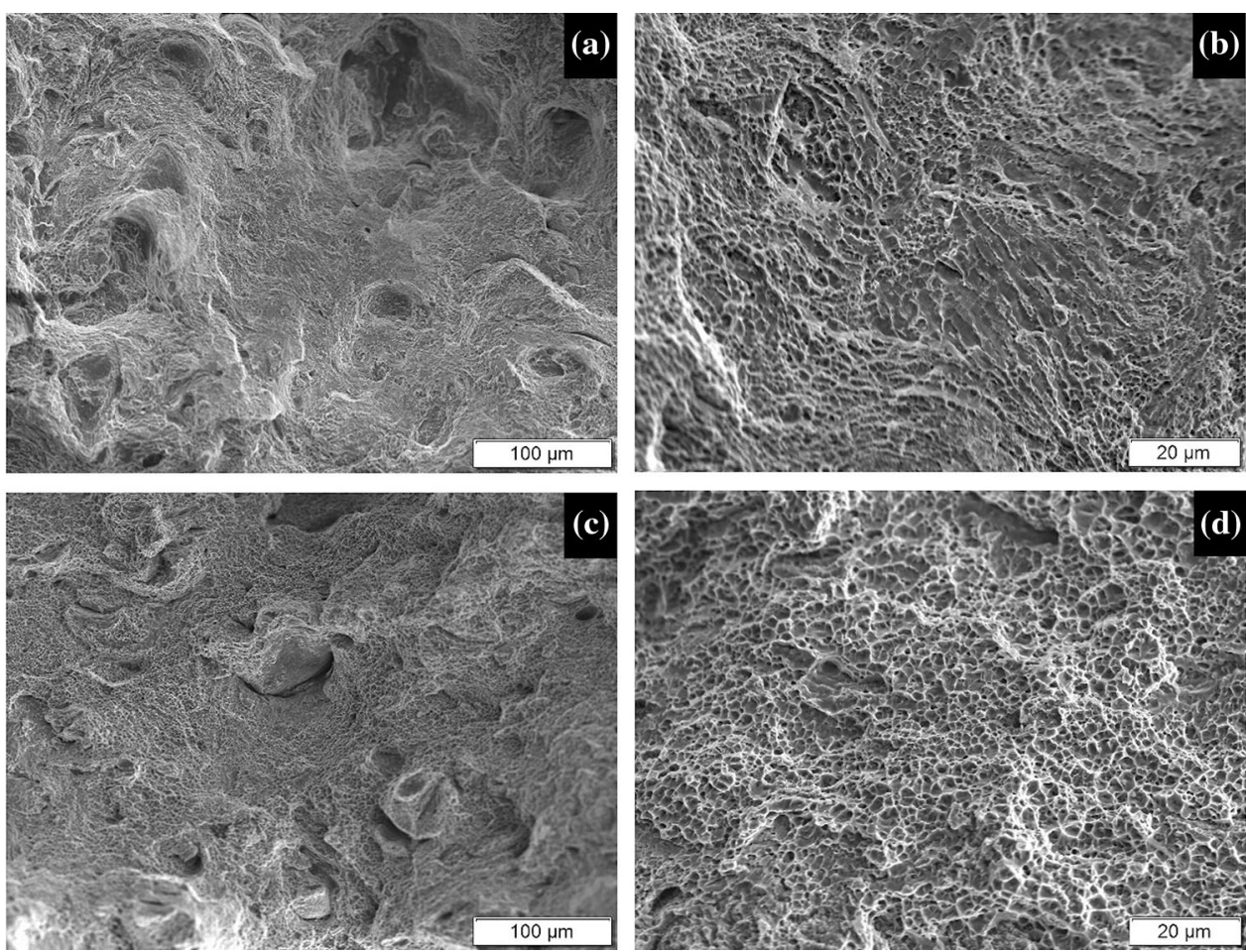

spheroidization of the $\mathrm{Si}$ and $\mathrm{Mg}_{2} \mathrm{Si}$ phases, as compared to the as-atomized powder. All three phases were also identified inside the cold-sprayed deposits, confirming that the internal microstructure of the powder was retained in the cold-sprayed microstructure.

- The amount of secondary phases increased with the thermal treatments. These results were predicted with Thermo-Calc equilibrium calculations and confirmed with SEM image analysis techniques.

- The internal powder microstructure correlated well with nanoindentation results, as the powder nanohardness decreased with thermal treatment, given the corresponding increase in phase fraction, coarsening of secondary phases, and increase in dendrite size. Hardness testing of the cold-sprayed deposits followed a similar trend, while also indicating the strain hardening effects associated with particle impact in CS.

- Tensile testing of the cold-sprayed deposits demonstrates mechanical behavior comparable to permanent mold cast $\mathrm{Al} 357$ in the as-cast condition, nearing the properties of the T6-tempered casting. Future optimization of the powder heat treatments can be used to further improve the mechanical properties of the coldsprayed deposits.

Acknowledgments This work was funded by the United States Army Research Laboratory, Grant \#W911NF-15-2-0024. The authors would like to extend their gratitude to graduate student Bryer Sousa at Worcester Polytechnic Institute for his extensive assistance with the nanoindentation performed for this work.
Open Access This article is licensed under a Creative Commons Attribution 4.0 International License, which permits use, sharing, adaptation, distribution and reproduction in any medium or format, as long as you give appropriate credit to the original author(s) and the source, provide a link to the Creative Commons licence, and indicate if changes were made. The images or other third party material in this article are included in the article's Creative Commons licence, unless indicated otherwise in a credit line to the material. If material is not included in the article's Creative Commons licence and your intended use is not permitted by statutory regulation or exceeds the permitted use, you will need to obtain permission directly from the copyright holder. To view a copy of this licence, visit http://creativecommons. org/licenses/by/4.0/.

\section{References}

1. I. Gibson, D.W. Rosen, and B. Stucker, Introduction and Basic Principles, Additive Manufacturing Technologies, (Boston, MA), Springer US, 2010, pp. 1-16, https://doi.org/10.1007/978-1-44191120-9.

2. W.E. Frazier, Metal Additive Manufacturing: A Review, $J$. Mater. Eng. Perform., 2014, 23(6), p 1917-1928. https://doi.org/ 10.1007/s11665-014-0958-z

3. K.V. Wong and A. Hernandez, A Review of Additive Manufacturing, ISRN Mech. Eng., 2012, https://doi.org/10.5402/2012/ 208760

4. S.H. Huang, P. Liu, A. Mokasdar, and L. Hou, Additive Manufacturing and Its Societal Impact: a Literature Review, Int. J. Adv. Manuf. Technol., 2013, 67(5-8), p 1191-1203. https://doi.org/10. 1007/s00170-012-4558-5

5. F.P.W. Melchels, M.A.N. Domingos, T.J. Klein, J. Malda, P.J. Bartolo, and D.W. Hutmacher, Additive Manufacturing of Tissues and Organs, Prog. Polym. Sci., 2012, 37(8), p 1079-1104. https://doi.org/10.1016/j.progpolymsci.2011.11.007 
6. A. Zocca, P. Colombo, C.M. Gomes, and J. Günster, Additive Manufacturing of Ceramics: Issues, Potentialities, and Opportunities, J. Am. Ceram. Soc., 2015, 98(7), p 1983-2001. https://doi. org/10.1111/jace. 13700

7. J.O. Milewski, Origins of Metal 3D Printing, Additive Manufacturing of Metals, Springer, Cham, 2017, https://doi.org/10. 1007/978-3-319-58205-4

8. I. Gibson, D.W. Rosen, and B. Stucker, Development of Additive Manufacturing Technology, Additive Manufacturing Technologies. Springer, Boston, 2010, p 17-40https://doi.org/10.1007/9781-4419-1120-9

9. D. Herzog, V. Seyda, E. Wycisk, and C. Emmelmann, Additive Manufacturing of Metals, Acta Mater., 2016, 117, p 371-392. https://doi.org/10.1016/j.actamat.2016.07.019

10. H.Z. Yu, M.E. Jones, G.W. Brady, R.J. Griffiths, D. Garcia, H.A. Rauch, C.D. Cox, and N. Hardwick, Non-Beam-Based Metal Additive Manufacturing Enabled by Additive Friction Stir Deposition, Scr. Mater., 2018, 153, p 122-130. https://doi.org/10. 1016/j.scriptamat.2018.03.025

11. F. Khodabakhshi and A.P. Gerlich, Potentials and Strategies of Solid-State Additive Friction-Stir Manufacturing Technology: a Critical Review, J. Manuf. Processes, 2018, 36, p 77-92. https:// doi.org/10.1016/j.jmapro.2018.09.030

12. T. Schmidt, F. Gärtner, H. Assadi, and H. Kreye, Development of a Generalized Parameter Window for Cold Spray Deposition, Acta Mater., 2006, 54(3), p 729-742. https://doi.org/10.1016/j. actamat.2005.10.005

13. O.G. Rivera, P.G. Allison, J.B. Jordon, O.L. Rodriguez, L.N. Brewer, Z. McClelland, W.R. Whittington, D. Francis, J. Su, R.L. Martens, and N. Hardwick, Microstructures and Mechanical Behavior of Inconel 625 Fabricated by Solid-State Additive Manufacturing, Mater. Sci. Eng. A, 2017, 694, p 1-9. https://doi. org/10.1016/j.msea.2017.03.105

14. M.R. Rokni, C.A. Widener, and G.A. Crawford, Microstructural Evolution of $7075 \mathrm{Al}$ Gas Atomized Powder and High-Pressure Cold Sprayed Deposition, Surf. Coat. Technol., 2014, 251, p 254263. https://doi.org/10.1016/j.surfcoat.2014.04.035

15. H.K. Rafi, N.V. Karthik, H. Gong, T.L. Starr, and B.E. Stucker, Microstructures and Mechanical Properties of Ti6Al4V Parts Fabricated by Selective Laser Melting and Electron Beam Melting, J. Mater. Eng. Perform., 2013, 22(12), p 3872-3883. https://doi.org/10.1007/s11665-013-0658-0

16. R. Li, P. Niu, T. Yuan, P. Cao, C. Chen, and K. Zhou, Selective Laser Melting of an Equiatomic CoCrFeMnNi High-Entropy Alloy: Processability, Non-Equilibrium Microstructure and Mechanical Property, J. Alloys Compd., 2018, 746, p 125-134. https://doi.org/10.1016/j.jallcom.2018.02.298

17. S. Palanivel, P. Nelaturu, B. Glass, and R.S. Mishra, Friction Stir Additive Manufacturing for High Structural Performance through Microstructural Control in an Mg Based WE43 Alloy, Mater. Des., 2015, 65, p 934-952. https://doi.org/10.1016/j.matdes.2014. 09.082

18. S. Marx, A. Paul, A. Köhler, and G. Hüttl, Cold Spraying: Innovative Layers for New Applications, J. Therm. Spray Technol., 2006, 15(2), p 177-183. https://doi.org/10.1361/ 105996306X107977

19. M.F. Smith, Comparing Cold Spray with Thermal Spray Coating Technologies, The Cold Spray Materials Deposition Process, Woodhead Publishing, Cambridge, 2007, p 43-61https://doi.org/ 10.1533/9781845693787.1.43

20. V.K. Champagne, Repair of Magnesium Components by Cold Spray Techniques, The Cold Spray Materials Deposition Process, Woodhead Publishing, Cambridge, 2007, p 327-352https://doi. org/10.1533/9781845693787.3.327
21. V.K. Champagne and D.J. Helfritch, Mainstreaming Cold Spray-Push for Applications, Surf. Eng., 2014, 30(6), p 396403. https://doi.org/10.1179/1743294414Y.0000000277

22. J. Karthikeyan, The Advantages and Disadvantages of the Cold Spray Coating Process, The Cold Spray Materials Deposition Process, Woodhead Publishing, Cambridge, 2007, p 62-71https:// doi.org/10.1533/9781845693787.1.62

23. K. Ogawa, K. Ito, K. Ichimura, Y. Ichikawa, S. Ohno, and N. Onda, Characterization of Low-Pressure Cold-Sprayed Aluminum Coatings, J. Therm. Spray Technol., 2008, 17(5-6), p 728735. https://doi.org/10.1007/s11666-008-9254-5

24. V.K. Champagne, The Repair of Magnesium Rotorcraft Components by Cold Spray, J. Failure Anal. Prev., 2008, 8(2), p 164175. https://doi.org/10.1007/s11668-008-9116-y

25. V.S. Bhattiprolu, K.W. Johnson, and G.A. Crawford, Influence of Powder Microstructure on the Microstructural Evolution of AsSprayed and Heat Treated Cold-Sprayed Ti-6Al-4V Coatings, $J$. Therm. Spray Technol., 2019, 28(1-2), p 174-188. https://doi.org/ 10.1007/s11666-018-0812-1

26. K. Tsaknopoulos, C. Walde, V. Champagne, and D. Cote, GasAtomized Al 6061 Powder: Phase Identification and Evolution During Thermal Treatment, JOM, 2019, 71(1), p 435-443. https:// doi.org/10.1007/s11837-018-3175-7

27. C. Walde, K. Tsaknopoulos, V. Champagne, and D. Cote, The Microstructural Evolution of Rapidly Solidified Powder Aluminum 2024 During Thermal Processing, Metallogr. Microstruct. Anal., 2019, 8(3), p 415-425. https://doi.org/10.1007/s13632-01900535-2

28. C. Walde, K. Tsaknopoulos, V. Champagne, and D. Cote, Phase Transformations in Thermally Treated Gas-Atomized Al 7075 Powder, Metallogr. Microstruct. Anal., 2020, 9(3), p 419-427. https://doi.org/10.1007/s13632-020-00641-6

29. C. Walde, D. Cote, V. Champagne, and R. Sisson, Characterizing the Effect of Thermal Processing on Feedstock Al Alloy Powder for Additive Manufacturing Applications, J. Mater. Eng. Perform., 2019, 28(2), p 601-6https://doi.org/10. https://doi.org/10. $1007 / \mathrm{s} 11665-018-3550-0$

30. A. Sabard, P. McNutt, H. Begg, and T. Hussain, Cold Spray Deposition of Solution Heat Treated, Artificially Aged and Naturally Aged Al 7075 Powder, Surf. Coat. Technol., 2020, 385, p 1-11. https://doi.org/10.1016/j.surfcoat.2020.125367

31. T. Liu, W.A. Story, and L.N. Brewer, Effect of Heat Treatment on the $\mathrm{Al}-\mathrm{Cu}$ Feedstock Powders for Cold Spray Deposition, Metall. Mater. Trans. A, 2019, 50(7), p 3373-3387. https://doi. org/10.1007/s11661-019-05230-z

32. A. Aversa, G. Marchese, A. Saboori, E. Bassini, D. Manfredi, S. Biamino, D. Ugues, P. Fino, and M. Lombardi, New Aluminum Alloys Specifically Designed for Laser Powder Bed Fusion: a Review, Mater., 2019, 12(7), p 1-19. https://doi.org/10.3390/ ma12071007

33. K. Schmidtke, F. Palm, A. Hawkins, and C. Emmelmann, Process and Mechanical Properties: Applicability of a Scandium Modified Al-Alloy for Laser Additive Manufacturing, Phys. Procedia, 2011, 12, p 369-374. https://doi.org/10.1016/j.phpro.2011.03.047

34. D. Buchbinder, W. Meiners, K. Wissenbach, and R. Poprawe, Selective Laser Melting of Aluminum Die-Cast Alloy-Correlations Between Process Parameters, Solidification Conditions, and Resulting Mechanical Properties, J. Laser Appl., 2015, 27(S2), p 1-6. https://doi.org/10.2351/1.4906389

35. H. Rao, S. Giet, K. Yang, X. Wu, and C.H.J. Davies, The Influence of Processing Parameters on Aluminium Alloy A357 Manufactured by Selective Laser Melting, Mater. Des., 2016, 109, p 334-346. https://doi.org/10.1016/j.matdes.2016.07.009

36. S. Jana, R.S. Mishra, H.N. Choi and D.R. Herling, Friction Stir Microstructural Modification of Investment Cast F357, in Proceedings of the 2007 Minerals, Metals, and Materials Society 
Annual Meeting, Feb 25- Mar 12007 (Orlando, Florida), The Minerals, Metals \& Materials Society (TMS), 2007, pp. 439-448.

37. H. Möller, G. Govender, and W. Stumpf, Comparison of the Heat Treatment Response of SSM-HPDC 6082 and 6004 Wrought Alloys with A356 and F357 Casting Alloys, Mater. Sci. Forum, 2011, 690, p 53-56. https://doi.org/10.4028/www.scientific.net/ MSF.690.53

38. K. Petráčková, J. Kondás, and M. Guagliano, Mechanical Performance of Cold-Sprayed A357 Aluminum Alloy Coatings for Repair and Additive Manufacturing, J. Therm. Spray Technol., 2017, 26(8), p 1888-1897. https://doi.org/10.1007/s11666-0170643-5

39. VELO3D, "VELO3D Develops Process for 3D Printing Aluminum F357 for Thin-Walled Heat Transfer Applications", 2020, In Press, https://www.velo3d.com/press-release/velo3d-developsaluminum-f357/. Accessed 1 June 2020.

40. GE Additive, "AP\&C to offer aluminum alloy F357 powder from April 2019”, 2018, In Press, https://www.ge.com/additive/pressreleases/apc-offer-aluminum-alloy-f357-powder-april-2019. Accessed 1 June 2020.

41. "Standard Guide for Determination of Various Elements by Direct Current Plasma Atomic Emission Spectrometry", E1097, ASTM International, 2012, pp. 1-8.

42. "Standard Specification for Aluminum-Alloy Permanent Mold Castings", B108/B108M, ASTM International, 2019, pp. 1-23.

43. Nanomechanics, Inc., "Nano- versus Micro-Indentation Hardness," n.d., In Press, http://nanomechanicsinc.com/indentationhardness/. Accessed 4 November 2020.

44. B.C. Sousa, C. Walde, Jr., V.K. Champagne, A.T. Nardi, Jr., R.D. Sisson, and D.L. Cote, Rapidly Solidified Gas-Atomized Aluminum Alloys Compared with Conventionally Cast Counterparts: Implications for Cold Spray Materials Consolidation, Coat., 2020, 10(11), p 1-28. https://doi.org/10.3390/coatings10111035

45. W. Yan, C.L. Pun, Z. Wu, and G.P. Simon, Some Issues on Nanoindentation Method to Measure the Elastic Modulus of Particles in Composites, Compos. B, 2011, 42(8), p 2093-2097. https://doi.org/10.1016/j.compositesb.2011.05.002

46. B.C. Sousa, M.A. Gleason, B. Haddad, V.K. Champagne, A.T. Nardi, and D.L. Cote, Nanomechanical Characterization for Cold Spray: from Feedstock to Consolidated Material Properties, Met., 2020, 10(9), p 1-70. https://doi.org/10.3390/met10091195

47. "Standard Test Methods for Tension Testing of Metallic Materials", E8/E8M, ASTM International, 2016, pp. 1-30.

48. L. Pedersen and L. Arnberg, The Effect of Solution Heat Treatment and Quenching Rates on Mechanical Properties and Microstructures in AlSiMg Foundry Alloys, Metall. Mater. Trans. A, 2001, 32(3), p 525-532. https://doi.org/10.1007/s11661001-0069-y

49. W. Li, S. Li, J. Liu, A. Zhang, Y. Zhou, Q. Wei, C. Yan, and Y. Shi, Effect of Heat Treatment on AlSi10Mg Alloy Fabricated by Selective Laser Melting: Microstructure Evolution, Mechanical Properties and Fracture Mechanism, Mater. Sci. Eng. A, 2016, 663, p 116-125. https://doi.org/10.1016/j.msea.2016.03.088

50. Y. Birol, Effect of Solution Heat Treatment on the Age Hardening Capacity of Dendritic and Globular AlSi7Mg0.6 Alloys,
Int. J. Mater. Res., 2010, 101(3), p 439-444. https://doi.org/10. 3139/146.110293

51. MT Abou El-khair, Microstructure Characterization and Tensile Properties of Squeeze-Cast AlSiMg Alloys, Mater. Lett., 2005, 59(8-9), p 894-900. https://doi.org/10.1016/j.matlet.2004.11.041

52. Z. Huda and T. Zaharinie, Kinetics of Grain Growth in 2024-T3: an Aerospace Aluminum Alloy, J. Alloys Compd., 2009, 478(1-2), p 128-132. https://doi.org/10.1016/j.jallcom.2008.11. 071

53. E. Ogris, A. Wahlen, H. Lüchinger, and P.J. Uggowitzer, On the Silicon Spheroidization in Al-Si Alloys, J. Light Met., 2002, 2(4), p 263-269. https://doi.org/10.1016/S1471-5317(03)00010-5

54. E.O. Hall, The Deformation and Ageing of Mild Steel: III, Discussion of Results, Proc. Phys. Soc. Sect. B, 1951, 64(9), p $747-$ 753. https://doi.org/10.1088/0370-1301/64/9/303

55. N.J. Petch, The Cleavage Strength of Polycrystals, J. Iron Steel Inst., 1953, 174, p 25-28

56. W.D. Nix and H. Gao, Indentation Size Effects in Crystalline Materials: a Law for Strain Gradient Plasticity, J. Mech. Phys. Solids, 1998, 46(3), p 411-425. https://doi.org/10.1016/S00225096(97)00086-0

57. Y. Zou, D. Goldbaum, J.A. Szpunar, and S. Yue, Microstructure and Nanohardness of Cold-Sprayed Coatings: Electron Backscattered Diffraction and Nanoindentation Studies, Scr. Mater., 2010, 62(6), p 395-398. https://doi.org/10.1016/j.scripta mat.2009.11.034

58. D. Goldbaum, R.R. Chromik, S. Yue, E. Irissou, and J.-G. Legoux, Mechanical Property Mapping of Cold Sprayed Ti Splats and Coatings, J. Therm. Spray Technol., 2011, 20(3), p 486-496. https://doi.org/10.1007/s11666-010-9546-4

59. M.R. Rokni, C.A. Widener, A.T. Nardi, and V.K. Champagne, Nano Crystalline High Energy Milled 5083 Al Powder Deposited Using Cold Spray, Appl. Surf. Sci., 2014, 305, p 797-804. https:// doi.org/10.1016/j.apsusc.2014.04.010

60. L. Ajdelsztajn, J.M. Schoenung, B. Jodoin, and G.E. Kim, Cold Spray Deposition of Nanocrystalline Aluminum Alloys, Metall. Mater. Trans. A, 2005, 36(3), p 657-666. https://doi.org/10.1007/ s11661-005-0182-4

61. J.G. Kaufman, "Table 6b. Approximate Typical Mechanical Properties of Cast Aluminum Alloys (Metric Units).," Aluminum Alloy Database, Knovel, 2015. https://app.knovel.com/hotlink/ itble/rcid:kpAAD00001/id:kt00UBBS21/aluminum-alloy-data base/table-6b-approximate. Accessed 17 July 2020.

62. R. Huang, M. Sone, W. Ma, and H. Fukanuma, The Effects of Heat Treatment on the Mechanical Properties of Cold-Sprayed Coatings, Surf. Coat. Technol., 2015, 261, p 278-288. https://doi. org/10.1016/j.surfcoat.2014.11.017

63. A.G. Gavras, D.A. Lados, V.K. Champagne, and R.J. Warren, Effects of Processing on Microstructure Evolution and Fatigue Crack Growth Mechanisms in Cold-Spray 6061 Aluminum Alloy, Int. J. Fatigue, 2018, 110, p 49-62. https://doi.org/10.1016/ j.ijfatigue.2018.01.006

Publisher's Note Springer Nature remains neutral with regard to jurisdictional claims in published maps and institutional affiliations. 